\title{
Creative Economy in Solidarity Economy: A Guide for New Policies
}

\author{
Diego Dias Rodrigues ${ }^{1}$, Nilo Costa Serpa ${ }^{1}$, Emilly Moura ${ }^{2}$, \\ Luiz Antonio Gouveia ${ }^{3}$, and José Benedito Sacomano ${ }^{1}$ \\ 1 UNIP - Universidade Paulista, \\ Graduate Program in Production Engineering, Brazil \\ 2 UNIP - Universidade Paulista, Undergraduate Program in Engineering, Brazil \\ 3 MINC - Ministry of Culture, Secretary of Creative Economy, Brazil \\ diego@unip.br, \{niloserpa, emillymcruz,luizantonio70,jbsacomano\}@gmail.com \\ http://www.unip.br
}

\begin{abstract}
This article was prepared with the purpose of analyzing solidarity economy from the standpoint of its manifestations of creativity, thus fomenting a contribution to the study of the so-called creative economy. This contribution will be investigated in Brazil, Third World country where solidarity initiatives have gained strenght since the early 2000s and where creative talent with regard to survival seems to have no limits. The information compiled and discussed here as an aid to the socio-economic knowledge of the country are intended to provide guidance for new public policies of solidarity that envisage creativity as the main foundation of the success of an economy whatever its market status.
\end{abstract}

Keywords: creativity, solidarity, economy, creative industry.

\section{Introduction}

Creativity is the fuel of the evolution of human kind. Culture is the way man burns that fuel to survive, controling nature and giving aesthetic sense to his life. During past decade, many works have been written on the role that criativity plays in economy ([4]; 9$]$; 10]), but not yet in depth enough to embrace solidarity economy. Even in van der Pol's article, from UNESCO Institute for Statistics, Canada, in which he recognizes that many stakeholders are involved in creative economy process, as cultural public institutions, non-profit sectors which may receive government subsidies and non-governmental organizations [13], nothing was said about solidarity initiatives. Among few authors, Allard and Matthaei referred to the global movement towards the initiatives of solidarity economy as courageous, creative, and diverse [1]; also Wainwright recently emphasized criativity as a determinant labour feature that has to be at the centre of the economy, including solidarity economy [14. In fact, what we now call "creative industry", and more generally "creative economy", is a new discipline which refers mainly, and almost exclusivly, to the impact of business creativity on the global market, with no great concerns to solidarity and social economy.

B. Grabot et al. (Eds.): APMS 2014, Part II, IFIP AICT 439, pp. 302 309 2014.

(C) IFIP International Federation for Information Processing 2014 
The concept of innovation is intrinsically linked to the concept of creative economy and the latter strongly linked to the solidarity economy in Brazil. Innovation today corresponds to both the improvement of what already exists and the proposal for something new. However, in particular, we commonly draw attention on creative segments such as architectural design and information technology due to the great integration between technological acquisitions and cultural aspects, but solidarity economy as the whole of economic activities of production, distribution, consumption and credit arranged in the form of self-management also encompasses many creative segments, a fact that justifies our researches on creative and solidarity economy together. In order to prevent inappropriate objections, the authors emphasize that this article refers to the study of creative manifestations closely linked to solidarity economy in their forms practiced in Third World, especially in Brazil.

\section{Theoretical Frame}

In present article, we understand solidarity economy as a collaborative way of producing, selling, buying and exchanging all that is necessary to survival. This collaborative work presumes mainly no exploitation of workers and no wanting to take advantage. Sometimes, we may refer to "social economy" as a synonym of solidarity economy.

This social economy comprises many economic and community practices organized in the form of cooperatives, associations, self-managed enterprises and cooperation networks, which produce goods, provide services, trade and fair trade consumption. Also, solidarity economy appears in emerging countries as an alternative to scarce and precarious formal jobs, but it would be wrong to think solidarity economy only as a form of refuge for the unemployed people, as noted by Kraychete et al. [7]. According to the Digital Atlas of Solidarity Economy (Brazil, 2007-2009), about 30\% of solidarity enterprises were due to search for an alternative to unemploymen [11. Although solidarity economy is, socially speaking, a set of valuable initiatives with great productive potential, little attention has been given to creativity clearly present in several solidarity enterprises.

Creativity is the essence of human evolution. There is nothing new to exalt it. What is new is to consider the creative potential of an enterprise as a collective manifestation of teams to be encouraged and valued by public policies that consider human capital as the only true asset to give materiality for the economic and social development of a nation. Only this will bring technological and scientific independence. There is no obligation to be creative, since innovation is a natural result of brain functions; it is just enough to stimulate the brain to produce innovation. One of the main results of this stimulus is the growth in worker's life quality, once he starts to look at himself as a productive and helpful person. Nevertheless, we must be careful to avoid incurring in the neo-liberal trap of assuming creativity as an intangible individual asset to be galvanized by a covert form of capitalist exploitation obliging workers to be creative, if they 
want to keep their jobs, as suggested by the Anglo-Saxon culture where the term "creative industry" was coined (it seems to have been born in Australia during the $90 \mathrm{~s}$, hence no wonder that the most organized data on creative economy come from the UK). Peuter points out as the European discourse ignores the precarious employment situation [3] in which, one by one, all activities classified within the creative industry are now crumbling beneath the chronic crisis of capitalism, which will end only when governments and companies finally understand that its model of exploitation and profit at any price irretrievably collapsed.

The geographical variety of Brazil offers natural barriers that hinder the access of census groups. Thereby, from the total amount of registered known solidarity enterprises, we can draw those belonging to the segments clearly linked to creativity such as textile and handicraft production, disregarding for the moment the industrial sector for its generality. This corresponds to $28 \%$ of the enterprises, a non-ignorable percentage.

\section{How Creativity can be Valued in Solidarity Economy}

Before presenting the subject of this section, the authors would like to make some observations about modern scientific postures. Hermann Bondi, undoubtedly one of the most eminent physicists of the XX century, noted that the scientist is someone who will never know all the facts, simply because every time something new happens. He concluded that an essential characteristic of science is the ability to describe things so that we can say something without knowing anything [2]. Unfortunately, there was developed, over the last thirty years, a postmodern culture almost completely restricted to the circular reading of articles, leaving aside the critical reading of the great classics that supported and consolidated the knowledge which will build the world of the XXI century. Two results of this abandonment were 1)- the introduction of a generalized inability to realize that to make simple and meaningful things is what is really difficult - indeed, the most universal physical principles are represented by the most simple equations - , and 2)- the incapacity to elaborate conjectures to subject them to tests of refutation. Many modern researchers have difficulty to building models from theoretical conjectures because they have been accustomed to working just about collected data. Only those conjectured models, subsequently subjected to systematic testing, may bring novelty and possibility of observation of hitherto unsuspected aspects. The model which will be presented here, fortunately, belongs to this theoretical category.

From the standpoint of solidarity economy in the third world, what matters are enterprises that aggregate values which are typically derived from creative attitudes; while they may be assigned to individuals, they are shared among the group members and begin to symbolize a joint effort without the capitalist parasitism with all its hate for communities where there is no exploitation of the workforce. 
The common classification of creative industries 12 includes:

Advertising, Architecture, Art and Antiques, Crafts, Design, Designer Fashion, Film and Video, Interactive Leisure Software, Music, Performing Arts, Publishing, Software and Computer Services, Television and Radio.

Obviously this is a biased classification in European discourse, since there is no reasonable argument to disregard any human activity as being not likely to assume acts of creation. The creative entrepreneurship itself has become a true philosophy of organizational leadership in the twenty-first century [5]. Even those segments can be said to be the most creative at this moment, since we know that music became a jumble of meaningless banalities and architecture became a barn of futuristic nonsenses, result of an exhibitionism completely distant from the society to which it should serve. Also television, radio and film show complete decay, both in quality of processes and in quality of scripts. What is observed is the great precariousness of work reflected in these sectors in terms of lack of social focus, lack of cultural quality and the almost complete absence of an aesthetic that guides public policies that promote success of economies based on the cultural and biological dimensions, thus building the necessary foundations for promoting real social evolution.

Perhaps, it would be interesting to adopt the following Brazilian definition: the creative industries are those in which productive activities are processes that primarily need a creative act to generating a product, good or service whose symbolic dimension determine its value, resulting in production of cultural, economic and social wealth 8 . Following a global trend, the Ministry of Culture of Brazil launched the Plan of the Secretary of the Creative Economy (2011-2014), the youngest Secretary of this Ministry, following the increased attention that the topic has been gaining in international discussions involving the UNPD (United Nations Program for Development), UNESCO (United Nations Educational, Scientific and Cultural Organization) and UNCTAD (United Nations Conference on Trade and Development).

Since there is creativity in all human productive actions, it will be interesting to compute the "creative impact" of other categories of solidarity enterprises. It would be very difficult to estimate this impact in absolute terms, so let us translate it to a dummy number of creative initiatives that correspond to the above impact. So, we established the formula

$$
I=\frac{1-N_{S c}}{N_{S c}} \times n / 100,
$$

where $I$ is the creative impact, $N_{S c}$ is the percentage number of typically creative solidarity enterprises, and $n$ is the number of degrees of freedom not typically creative, ie, the number of remaining categories of solidarity enterprises. The result will be added to the percentage of creative solidarity enterprises, thus making the final virtual percentage in creative enterprises.

There are several classifications of creative economic sectors; there is no consensus on the matter. Thus, the degrees of freedom vary according to the interpretations of the structural characteristics of creative production. The creative categories listed above do not correspond to the universe of the solidarity 


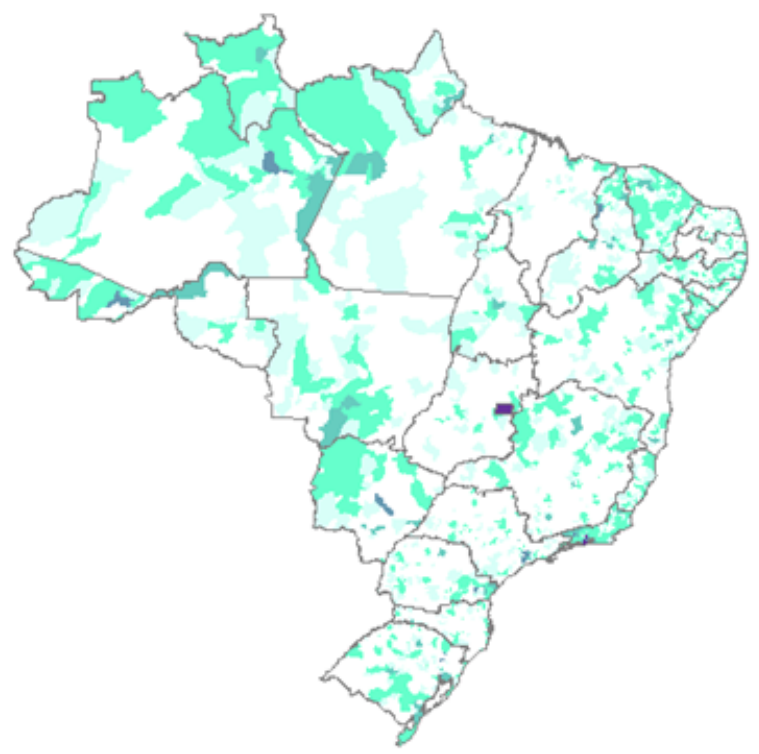

Quantity

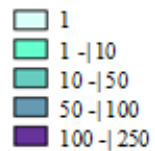

Fig. 1. Distribution of typically creative enterprises in Brazil

economy, at least not in the Third World. We need a rating closer to the scenarios of social economies in emerging countries. Let us consider the real situation. In accordance with the National Information System of Solidarity Economy, Brazil, the major economic sectors are:

1. Services (Miscellaneous)

2. Agricultural Production, Extraction and Fishing

3. Production of Handcrafted Artifacts *

4. Production of Herbal Medicines, Cleanliness and Hygiene

5. Production and Service of Food and Beverage

6. Production and General Services

7. Industrial Production (Miscellaneous)

8. Mineral Production (Miscellaneous)

9. Textile and Garment Production *

10. Collection Services and Materials Recycling

11. Services Relating to Credit and Finance

Figure 1 maps the distribution of creative segments 3 and 9 . The Northern, Northeast and Midwest regions concentrate the most typically creative solidarity enterprises. Except for those marked with an asterisk, which refer to typically creative enterprises, there are nine degrees of freedom to be considered in the above defined equation. Thus,

$$
I=\frac{1-0.28}{0.28} \times 9 / 100=0.23,
$$




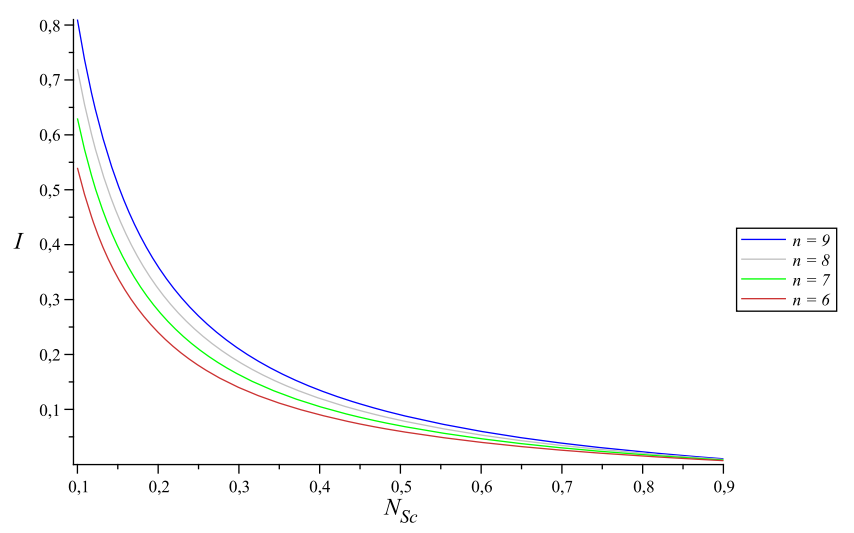

Fig. 2. The theoretical evolution of criative impact of general solidarity enterprises in a society that encourages innovation in all economic segments

from which we obtain the final virtual percentage,

$$
F_{\%}=0.28+0.23=0.51
$$

or $51 \%$. Thus, we say that about $51 \%$ of the solidarity economy activities manifest considerable degree of creativity. Figure 2 shows how the weight of creative participation of generic productive segments evolves with the relative increase in typically creative enterprises, for different numbers of degrees of freedom. Clearly, the greater the adhesion to policies that encourage innovation projects, the less the creative impact by the simple reason that at the end there will remain no less creative enterprises. What is our intention with this result? Firstly, to show how one should regard creative economy inside the context of solidarity economy in Third World, thus avoiding distortions and concept vices of origin. Second, to estimate the weight of creativity in order to better guide public investment policies in solidarity / creative economy, so that we can establish our own paths of social progress.

\section{Discussion}

When we seek to mathematically formalize a new hypothesis or set of new hypotheses, we are trying to establish a theoretical model to be further tested and refined through continuous observation and comparison with data from experience. In this study, the proposed formula seeks to establish an evolutionary indicator of the creative economy in the context of the solidarity economy as it stands today in Brazil, so that we can set some initial parameters for the monitoring of the national scenery. 


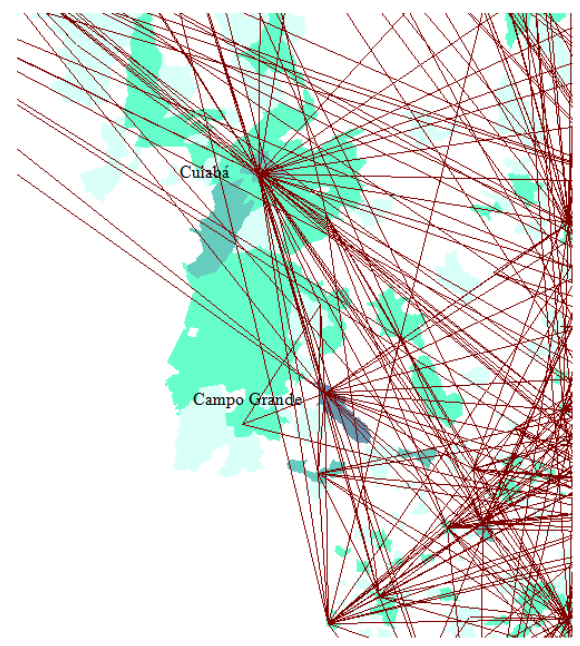

Fig. 3. Airway grid on Midwest region (same legend of Figure 1)

There are very few studies conducted on creative economy in Brazil. These studies need to be directed primarily to the forms of social economy, since in emerging countries there are great deficiencies in public policies that promote the welfare of disadvantaged work forces beneath the defilements of neoliberalism. In Third World, confronting to the present market-driven and neo-liberal economy, the umpteen set of solidarity enterprises are known wanting from the goal of a great integrative and socializing way of development, being more restricted to local challenges of survival and livelihood. For instance, in Asia, the general tendency of social enterprises is to work in isolation [6]. Nevertheless, stimulate and enhance creativity in solidarity enterprises, dividing the merit among the members of the production team and encouraging collaborative behavior as the respect and recognition of individual natural leaders, whether in the field of creation as in the field of ideas in general, can be the way to impart to people the ethical principles of solidarity behaviour as components of a culture of social responsibility and reciprocity in order to constitute a real and solid way of life. Art an criativity are fundamental to transforming ethnocentric person's mindset to one exhibiting compassion for other people, a work absolutely necessary for the success of solidarity culture.

Despite the emphasis on innovation, it is not enough to motivate the solidarity economy without creating a corresponding transport and telecommunication infrastructure to ensure accessibility to products and therefore to people. The Midwest region, for instance, is virtually transparent to the Airway grid with few options of boarding (see Figure 3). Also capillarity by paved roads shows deficient. As we can see, investments for the true creative industry of Brazilian people - linked to social economy enterprises - are heavy and demand long term planning; Zamora was not achieved in a single negotiation. 


\section{Conclusion}

This article discussed how it is possible to analyze the creative economy from the standpoint of solidarity economy, showing the need to build an adequate innovative production model for all Third World countries. It pointed out that debates on creative economy in Brazil can not be conducted in use of the AngloSaxon jargon, because this does not fit the reality of the country. It also showed how the emphasis on creativity can motivate the emergence of a culture of solidarity. This paper initiates a collaborative effort between academic researchers and managers of MINC - Ministry of Culture of Brazil - to support decision making in setting parameters for creative economy policies. It is also expected to continue this research in collaboration with other government agencies such as SENAES - National Secretariat of Solidarity Economy.

\section{References}

1. Allard, J., Matthaei, J.: Solidarity economy - Building alternatives for people and planet. Papers and Reports from the U.S. Social Forum (2007)

2. Bondi, H.: Assumption and myth in physical theory. Portuguese translation from Paulo César de Morais, pp. 1-53. Editora Universidade de Brasília, Brasil (1997)

3. de Peuter, G.: Creative economy and labor precarity: A contested convergence. Journal of Communication Inquiry 35, 417-425 (2011)

4. Hendrickson, M., Lugay, B., Caldenty, E., Mulder, N., Alvarez, M.: Creative industries in the Caribbean: A new road for diversification and export growth. ECLAC Subregional Headquarters for the Caribbean, Port of Spain (2012)

5. Hagoort, G., Thomassen, A.: On the entrepreneurial principles of the cultural and creative industries (2007)

6. Jayasooria, D. (ed.): Developments in solidarity economy in Asia. JJ Resources, Malaysia (2013)

7. Kraychete, G., Costa, B., Lara, F. (orgs.): Economia dos setores populares: entre a realidade e a utopia. Vozes, Petrópolis (2000)

8. MINC - Ministério da Cultura: Plano da Secretaria da Economia Criativa - políticas, diretrizes e ações, 2011 a 2014. Ministério da Cultura, Brasília (2012)

9. Miles, I., Green, L.: Hidden innovation in the creative industries. NESTA, National Endowment for Science, Technology and the Arts, United Kingdon (2008)

10. Roodhouse, S.: The creative industries: definitions, quantification and practice. In: Eisenberg, C., Gerlach, R., Handke, C. (eds.) Cultural Industries: The British Experience in International Perspective. Humboldt University, Berlin (2006)

11. Serpa, N.: Atlas digital da economia solidária, versão para Internet, http://www.mte.gov.br/sistemas/atlas/AtlasES.html

12. UNCTAD - United Nations Conference on Trade and Development: Creative economy report 2008. UNCTAD/DITC/2008/2, United Nations (2008)

13. van der Pol, H.: Key role of cultural and creative industries in the economy. UNESCO Institute for Statistics, Canada (2011)

14. Wainwright, H.: Notes for a political economy of creativity and solidarity. In: Satga, V. (ed.) Solidarity Economy Alternative - Emerging Theory and Practice. University of KwaZulu Natal Press, Durban (2013) 